\section{International Scientific Journal Theoretical \& Applied Science}

p-ISSN: 2308-4944 (print) e-ISSN: 2409-0085 (online)

Year: $2016 \quad$ Issue: 3 Volume: 35

Published: $30.03 .2016 \quad$ http://T-Science.org
ZarifaValad gyzy Damirova

$\mathrm{PhD}$ in Physics and Mathematics, Associate Professor of the Department of Teaching Methods of Physics,

Sumgait State University zarifadamirova@hotmail.com

SECTION 21. Pedagogy. Psychology. Innovations in the field of education.

\title{
CONTEMPORARY APPROACHES TO TEACHER PROFESSIONAL DEVELOPMENT
}

\author{
Abstract: The article analyzes the current state and identifies perspectives of development ofprofessional \\ competence of teachers on training courses. \\ Key words: professional competence, teachers, teachers training. \\ Language: English \\ Citation: Damirova ZV (2016) CONTEMPORARY APPROACHES TO TEACHER PROFESSIONAL \\ DEVELOPMENT. ISJ Theoretical \& Applied Science, 03 (35): 113-116.

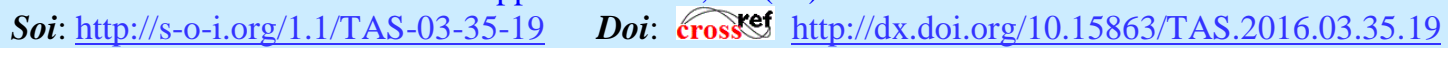

Statement of the problem in the general form and its connection with the important scientific and practical tasks. In the conditions of information society the modern teacher must not only possess professional knowledge and skills well, but also be able to adapt himself to the rapid processes both in the professional and public spheres of life, and use the means of new information technologies, be competent, able to participate actively in the public life, self-realize and constantly develop himself. Therefore, the problem of professional development of the teachers becomes very topical, and the issue arises what namely and how it is necessary to change on the enhancement training courses, in order that a modern teacher meeting the requirements of time could provide the high level knowledge acquisition by the pupils based on the modern approaches and methods of teaching.

The key moment of the development of modern pedagogue is formation of the professional competences both on the stage of basic functional training, and in post-graduate education, when a specialist realizes his life strategy "education during lifetime".

In the work [10] the essence of teacher's professional competence was determined as the aggregate of his personal characteristics, which provide the effective execution of the tasks and duties of pedagogical activity by him, and is a measure of correspondence of the professional activity.

It shows itself in the activity and can't be isolated from the concrete conditions of its implementation. The basic features of teacher's professional competence are professional knowledge, experience, motives, values and personal qualities. The conducted analysis of the scientific works and approaches to the determination of teacher's professional competence structure wholly allowed determining:

1) invariant constituents of the professional competence (general requirements, which can be demanded from any teacher): common cultural; legal-regulatory; psychological-pedagogical; selfdeveloping; information-computer competence;

2) variant constituents of the professional competence (the requirements, demanded exclusively from a teacher); the subject competence; activecommunicative competence.

However, the problem of improvement of the enhancement training courses of the teachers requires proper study.

The basic aim of the study is analysis of the modern state and search of prospective directions of the professional competence development of the teachers at enhancement training courses.

The modern system of pedagogues' postgraduate education builds its activity according to the following strategic directions:

- Modernization of the content, forms and methods of improvement training of the managerial and pedagogical staff;

- Scientific-methodical accompaniment of the education content renovation, monitoring and expertise of innovations, developed by the educational institutions, separate pedagogues, and 
external qualification expertise of the educational employees;

- Renovation and expansion of the functions, directions of postgraduate educational structure activity, improvement of the organizational and staff provision of the educational institution.

The compulsory element of modern distance education is implemented distance form of conducting the enhancement training courses, directed on the improvement of the education quality; development of the programmes of distance courses for teachers.

In the modern system of postgraduate education of Azerbaijan the enhancement training courses were implemented. These courses are compulsory for all pedagogues, in spite of the professional direction and level of qualification. The term of passing is 1 time in 5 years. The main task is satisfaction of the demand of each pedagogue in accordance with the qualification, audience experience and demand in deepening their knowledge.

Let's give an example of the typical educational plan of the teacher's enhancement training courses. It consists of three modules and is intended for 180 hours: totally 108 hours for auditorium and 72 hours for the independent work. The first module contains three substantial modules: social-humanitarian, psychological-pedagogical and methodical ones, totally 64 auditorium hours. The second module includes individual creative project of the audience on courses and their protection, totally 6 auditorium hours. The third module - 28 auditorium hours: pedagogical practice $-6 \mathrm{~h}$., auditorium practice -19 $h$. and examination -3 hours. The independent work provides possibility to deepen and fix theoretical knowledge, form practical skills connected with pedagogical activity of a teacher, execute the search of the most effective methods of teaching and educating of pupils, and also possibility to form the teachers' skills to work in the conditions of choice of the pedagogical problem, technology, modern didactic material, content and form of education.

The content of improvement training programme for teachers lies in the implementation of all tasks, required for achievement of the educational results of modules, and is executed by the way of:

- Considering the educational material on mini-lectures;

- Independent study of the educational material based upon the complex of educationalmethodical materials developed for the module;

Execution of the practical tasks, directed at the obtainment of the skills in practice to obtain theoretical knowledge;

Participation in the disputes, discussions, other types of group interaction with the purpose of critical thinking development;
Formation of the mindsets and qualities for using of the obtained knowledge and skills in the professional activity;

- Conduction of the introductory and source self-assessment of the physics teachers, summary control testing to a module [10].

Moreover, the audience of the teachers' enhancement training courses pass the pedagogical and auditorium practice.

Together with it, we must notice that the basic shortcoming of the enhancement training courses is insufficient frequency of courses. For 5 years the educational material, forms and methods of teaching can sufficiently change. It is confirmed by the opinion of V. G. Kremen', who states that today: “... the change of ideas, knowledge and technologies take place much faster than the changes of human generation" [5, p. 9].

In our opinion, with the purpose of solving this problem, it is necessary to use the interactive methods of teaching and reflection at the enhancement training courses.

One of the peculiarities of work with adults, as V. I. Putsov says, is their orientation on the immediate application of the results of education. On the assumption of this, it is appropriate to use the methods of interactive education, which correspond to the nature and typical signs of adult education. They allow not only optimally taking into account the educational demands of an adult person, but also creating the conditions for the constant, systemic analysis of own actions. The interactive education can prevent appearance of the patterns and stereotypes in relation to the professional activity in pedagogue's consciousness [9, p. 24-25].

The notion of "interactive education" in the science is considered as:

- education, deepened in the communication; preserves the final aim and basic content of the educational process, however, changes the forms from translational (transmitting) to the dialogue, i.e. based upon mutual understanding and interaction [4];

- special form of organization of the cognitive activity that has concrete intended aim of creating comfortable conditions of education, at which each one feels his success and intellectual ability [2, p. 18].

Organization of the interactive education supposes modelling of the life situations, using of role plays, common solution of the problem based upon the analysis of circumstances and corresponding situation. The interactive education effectively promote to formation of the habits and skills, development of the values, creation of the cooperation and interaction atmosphere.

Interactive methods of postgraduate education are considered as the system of subject-subjective relations (the teacher of postgraduate education system and pedagogue), which basis is acquisition of 
methods, education means and theory of their use for implementation of the education mission, represented in the educational aims of the subject by the pedagogue [8, p. 117].

The reflexive activity of the teacher-listener is no less important at passing the enhancement training courses as an indispensable attribute of the process of development of his professional competence.

In the modern science the notion of reflection is used in two basic meanings. Firstly, reflection is related to self-consciousness of a personality. Reflection is a principle of human thinking, which directs it on understanding of own preconditions; subject consideration of the knowledge itself; critical analysis of its content and methods; self-cognition activity that reveals internal structure and specificity of the spiritual human world. Secondly, reflection is considered as the process of reflecting of the world of other person by one person. Reflection is not only knowledge and understanding of the other, but also knowledge of that how this other understands "reflecting" individual [6].

The key problems of reflection in education include two directions: ontological (connected with the content of subject knowledge) and psychological (i.e. addressed to self-cognition and cognition of own activity) [3, p. 16].

The pedagogical reflection is connected with peculiarities of the content of pedagogical activity and with the experience of own work and is directed both on the own activity, activity of the colleagues, and on the pupils' activity. According to the own activity, the pedagogical reflection is characterized by understanding own pedagogical experience, development of the success criteria, and analysis of the changes, which take place in own education [7]. Reflection as one of the properties of personality is the basis of his self-development, openness to the new experience and other people; professional reflection provides accumulation of the new experience by the pedagogue and development of the pedagogical activity individual style is very important in the context of his professional development [1, p. 141].

Moreover, it should be noted that in the modern world the informatization of education is one of the priority directions of modernizing the native system of education, human training to life in the information society on the assumption of global transformation. This puts the certain range of requirements to the teacher: he must be able to work with computer equipment, own the certain information-computer technologies. Accordingly, teachers' training on the enhancement training courses should be done in the following directions:

training to teaching with assistance of information technologies;

training to using information media as the means of effective physics teaching; conduction of master classes on teaching one or other topics with using information technologies during demonstrations;

conduction of master classes, laboratory works with application of the innovation technologies;

obtainment of the skills of work with innovation technologies for the control and management of the pupils' work.

Consequently, within the frameworks of modernizing the teachers' enhancement training courses in the regional institute of postgraduate pedagogical education, it would be appropriate to increase the total meaning of activity, oriented on realization of the teachers' intellectual potential based upon the subject-subjective relations, dialogue and experience exchange with colleagues, in particular, improvement of his thinking, reflection and readiness to work with computer equipment and its wide application at the classes.

As it was said above, the development of new organizational forms, ways and methods of educations is accomplished all the time. Knowledge paradigm of education moves background. Attention is being increasingly focused on the development of dispositions obtained by a child in the heredity into the corresponding abilities. The new scientifically substantiated approaches to the development of pupils' creative abilities appeared. If earlier it was thought that for the development of human creative abilities it is necessary to involve him to solving the creative tasks (at that, the categories of creative tasks included the tasks with the algorithm of solution unknown for the subject), then now it is believed that it is needed to develop the feeling of harmony in a human, thus, he would be able to detect disharmony between the elements of certain system, in which the creativity lies [4]. Knowing it, teacher can organize the corresponding work with pupils and the development of own creative potential. A lesson is no more a single and impersonated didactical unit.

During the last decade the digital photo and video equipment also became popular. The substantial quantity of pupils use mobile telephones with photo and video cameras mounted in them, which can be used in the research of natural phenomena [3].

On the assumption of above-said it is possible to make several conclusions.

The system of postgraduate pedagogical education requires further development, as it is more dynamic and approached to the teachers' requests.

It is necessary to involve authors of pedagogical innovations or those teachers, who already successfully use them in their practical activity (the material is better perceived "from the first hand", to the conduction of classes at the teachers' enhancement training courses.

In the postgraduate education institutes, it is necessary to create libraries (instead of film archives, 


\begin{tabular}{l|lrl|l|ll} 
& ISRA (India) & $=\mathbf{1 . 3 4 4}$ & SIS (USA) & $=\mathbf{0 . 9 1 2}$ & ICV (Poland) & $=\mathbf{6 . 6 3 0}$ \\
Impact Factor: & ISI (Dubai, UAE) $=\mathbf{0 . 8 2 9}$ & PUHL (Russia) $=\mathbf{0 . 1 7 9}$ & PIF (India) & $=\mathbf{1 . 9 4 0}$ \\
& GIF (Australia) & $\mathbf{0 . 5 6 4}$ & ESJI (KZ) & $=\mathbf{1 . 0 4 2}$ & IBI (India) & $=\mathbf{4 . 2 6 0}$
\end{tabular}

known in the due time), which would include not only scientific, and scientific-popular video films, but also video records of the teachers' lessons bearers of the advanced pedagogical experience.

The development of professional competence of teachers on the improvement qualification courses can happen in the following directions: using the interactive methods of teaching, reflection and wide usage of information-computer technologies.

The problems of teachers' distant education implementation at the enhancement training courses requires further development.

\section{References:}

1. Zharovtsev TG (2002) Reflection in the pedagogical activity of a future specialist of pre-school education / T. G. Zharovtsev // Vestnik of PSPU named after K. D. Ushinskiy. - 2002. - Iss.10. - pp. 141-143.

2. Kovalchuk VI (2009) Innovation approaches to organization of the educational process in PTU: a special course for the improvement training of managerial and pedagogical staff of education / V. I. Kovalchuk. - Moscow: Shkolnyi mir, 2009. - $136 \mathrm{p}$.

3. Kovalchuk VI (2009) Technology of adults' education based upon the personal oriented approach: training / V. I. Kovalchuk. Moscow: Shkolnyi mir, 2009. - 136 p.

4. Korotaeva EV (2000) Director-teacher-pupil: ways of interaction / E. V. Korotaeva. Moscow: September, 2000. - 144 p.

5. Kremen' VG (2003) Education and science of Ukraine: ways of modernization (facts, reflections, perspectives) / V. G. Kremen'. - K.: Gramota, 2003. - 276 p.

6. Kulyutkin YN (2002) Axiological orientations and cognitive structures in the teacher's activity
/ Yu. N. Kulyutkin, V. P. Bezdukhov. Samara: SamSPU, 2002. - 400 p.

7. Kulyutkin YN (2002) Educational technology and pedagogical reflection / Yu. N. Kulyutkin, I. V. Mushtavinskaya. - SPb.: SPbSUPM, 2002. $-48 \mathrm{p}$.

8. (2007) Professional development of the pedagogues: practical andragogy: teaching aid / Ed. by V. I. Putsov, L. Ya. Naboki. - Moscow, 2007. - 228 p.

9. Putsov VI (2006) Andragogy problems in the teachers' training for the system of postgraduate education: text-book / V. I. Putsov. Chernovtsy: Bukrek, 2006. - 96 p.

10. Rusnak TA (2012) Competent approach as the conceptual basis for the physics teachers' improvement training / T. A. Rusnak, A. P. Andrukh // Educational space. Global, regional and information aspects: scientific-methodical journal. - Chernovtsy: Cheremosh, 2012. - Iss. 2 (8). - pp. 63-67. 